\title{
Neuropsychiatric systemic lupus erythematosus in elderly people: a case series
}

\author{
M S Dennis, E J Byrne, N Hopkinson, P Bendall
}

\begin{abstract}
Five elderly patients presenting with neuropsychiatric systemic lupus erythematosus were referred to the sectorised psychiatry service of the department of health care of the elderly. They represented $2 \%$ of patients admitted over a period of two years. Two patients presented with a subacute confusional state, two with dementia, and one with depression. Three patients responded well to treatment. This suggests that systemic lupus erythematosus (SLE) is more common in elderly people than was originally thought and is a potentially treatable cause of organic brain disorder. The absence of reports of elderly patients with SLE is likely to be due to the continued application of the American Rheumatism Association's revised 1982 classification criteria, which are inappropriate for this population.
\end{abstract}

(F Neurol Neurosurg Psychiatry 1992;55:1157-1161)

Cerebral manifestations of systemic lupus erythematosus (SLE) are common, ${ }^{12}$ appearing with a wide range of neurological and psychiatric features. These vary from mild and transient to severe and progressive. The commonest presentation of primary neuropsychiatric systemic lupus erythematosus (NPSLE) is an acute or subacute confusional state, which may appear in $20-40 \%$ of patients with SLE at some time during the course of the illness. ${ }^{3}$ Other common features include psychoses (usually schizophreniform), epilepsy, and stroke. Dementia, movement disorders, and cranial and peripheral neuropathy are other less common manifestations. ${ }^{124}$

Neuropsychiatric SLE often presents in isolation, occurring early in the course of the illness. As other characteristic symptoms of the disorder are absent, the diagnosis may become difficult and is often overlooked.

SLE in elderly people was previously described as rare; however, cases are increasingly being reported. Few studies have restricted themselves to elderly people, and those that have either contain few subjects ${ }^{5}$ or include those aged 50 as elderly. ${ }^{67}$ Most information has come from general population studies that include only a small proportion of elderly patients. ${ }^{89}$ A recent Scandinavian study that included an appreciable number of patients aged 60 or over suggested that the previously firmly held belief that SLE was principally a disorder of young women was untrue, and the peak incidence was in the age groups 55-64 and $65-74$ years. ${ }^{10}$ This study did not use the American Rheumatism Association's revised 1982 criteria (ARA criteria) except for classification, rather, it confirmed cases on evidence of a typical multisystem disease with characteristic immunological laboratory findings.

There is, however, general agreement on many of the features of SLE in elderly patients. The onset is insidious, often with symptoms preceding the diagnosis by many years. The presenting features often differ, constitutional symptoms and arthritis being common and cutaneous manifestations and lymphadenopathy rare. There seems to be no sex difference, and the illness runs a prolonged and benign course. Conflict arises over whether neurological and psychiatric disturbance is more frequent $^{56}$ or less frequent ${ }^{7}$ in elderly than in younger age groups. A series of patients from a recent Scandinavian study failed to clarify this issue. ${ }^{11}$ Of neuropsychiatric features in this age group, depression and organic brain syndromes are particularly common.

Considering these factors it is not surprising that the diagnosis may be missed or mistaken for other connective tissue disorders such as rheumatoid arthritis or polymyalgia rheumatica. One of the difficulties may be that the revised ARA criteria for the classification of systemic lupus erythematosus ${ }^{12}$ have been used in most clinical studies. For a definite diagnosis four or more of the 11 criteria need to be present serially or simultaneously. The criteria were devised to differentiate SLE from other connective tissue disorders in younger age groups and therefore may not be appropriate for the study of an illness of insidious onset with few classic features, as seen in elderly patients. It is a possibility that elderly patients with NPSLE will be seen by psychogeriatric services.

The following case series comprises five elderly patients presenting with neuropsychiatric manifestations of SLE. They were referred to the sectorised psychiatric services of our department of health care of the elderly. They represented five of 254 persons admitted for functional or organic illness over a period of 25 months (2\% of admissions).

\section{Case reports}

Case 1

A married 75 year old man presented to the psychogeriatric day hospital with a subacute confusional state of one month's duration. He 
appeared alert and orientated during the day but at night would become disorientated, incoherent, agitated, and verbally and physically aggressive. During these episodes, witnessed by his wife, he would also seem to be visually hallucinating and to be unsteady on his feet.

Five years previously he had been diagnosed as suffering from Parkinson's disease and was receiving levodopa $100 \mathrm{mg}$ and carbidopa $25 \mathrm{mg}$ three times daily. He was attending the day hospital for treatment of dysthymia, for which he was prescribed lofepramine $70 \mathrm{mg}$ twice daily.

A fall while wandering at night resulted in his admission to the inpatient unit for further investigation. During the early stages of the admission his behaviour accorded with his wife's description-namely, alert by day and acutely confused at night. $\mathrm{He}$ complained of symptoms of generalised myalgia and arthralgia. An arthropathy, bilateral Baker's cysts, and dry eyes were the only physical findings. Initial diagnosis was a subacute confusional state induced by levodopa, but manipulation of the dose of co-kareldopa led to no clinical change. A normal 24 hour electrocardiogram excluded cardiac arrythmia. The full blood count showed lymphopaenia with a peripheral lymphocyte count (PLC) of $0.4 \times 10^{9} / 1$. Immunological investigations revealed antinuclear antibody (IgG <25, IgM 100) and moderately raised concentrations of $\mathrm{C} 3$ degradation products. Tests for antibody to double stranded DNA (crithidia) had negative results. The only other abnormality was mild renal impairment.

On the basis of the history of subacute confusion, physical findings, and immunological abnormalities the patient was prescribed a course of prednisolone $20 \mathrm{mg}$ daily for six weeks. The response was dramatic, and azathioprine $150 \mathrm{mg}$ daily was added to allow a quicker reduction of prednisolone. Nocturnal confusion cleared and mobility, Parkinsonian features, and depression all improved. A diagnosis of SLE was made. For the past two years he has remained well while taking azathioprine $150 \mathrm{mg}$ daily.

Case 2

A 76 year old married woman presented with a major depressive episode of one month's duration. Accompanying this was a mild degree of cognitive impairment, principally affecting orientation and short term memory. There was no previous psychiatric illness.

She had been physically fit until retirement at 72 years of age. Since that time she had had four medical admissions. During the first, at age 74 , she was diagnosed as suffering from hypothyroidism and hypertension. Myalgia and hyponatraemia, possibly secondary to inappropriate production of antidiuretic hormone were noted. A year later she presented with foot ulcers, dizziness, and possible amaurosis fugax. Transient ischaemic attacks were diagnosed, but no comment had been made concerning the possible aetiology of the foot and leg ulcers. In the month preceding her psychiatric admission she had been admitted twice, first for chest pain, dizziness, and "confusion" no diagnosis has been made. The second admission was for a urinary tract infection. The medical staff commented that, she was "hypochondriacal", and the erythrocyte sedimentation rate remained raised $(56 \mathrm{~mm} / \mathrm{h})$ despite treatment of the urinary infection.

Her husband's inability to cope with her agitated depressive state led to her psychiatric admission. She had biological features and mild cognitive impairment affecting orientation in time and short term memory, with poor concentration. Results of physical examination were unremarkable. Mianserin $60 \mathrm{mg}$ at night, and thioridazine $10 \mathrm{mg}$ three times daily were started.

Initial investigations showed that the erythrocyte sedimentation rate was still raised $(50 \mathrm{~mm} / \mathrm{h})$, and there was a lymphopaenia (PLC $\left.=0.9 \times 10^{9} / 1\right)$. An electrocardiogram showed left ventricular hypertrophy, and a chest radiograph showed cardiomegaly with pleural calcification. Further immunological investigations were performed, revealing antinuclear antibody (IgG 400, IgM 400), antibody to double stranded DNA (IgM 80), antibody to $\operatorname{Ro}(\mathrm{SSA})$, and a greatly raised concentration of $\mathrm{C} 3$ degradation products. Antibodies to cardiolipin were also present (IgM 93, IgG 45), but tests for lupus anticoagulant had negative results.

In view of the history and characteristic immunological profile a diagnosis of SLE was made and the patient was given prednisolone $20 \mathrm{mg}$ daily for two months. There was considerable improvement in both her general and mental health, the prednisolone was gradually stopped, and azathioprine $100 \mathrm{mg}$ daily was introduced. She remained well for the next two years, but was then readmitted as an emergency and died of acute bronchopneumonia. Post mortem examination showed evidence of Libman-Sacks endocarditis.

\section{Case 3}

A 93 year old widow was admitted from a Part III home. Over recent months her mental and physical state had declined. She had become increasingly disorientated and forgetful and was incessantly shouting out perseverative and distressing phrases to anybody she saw. From being mobile with a frame she had become immobile and incontinent of urine and faeces.

Her medical history was complicated. Five years previously she had presented to the service with a subacute confusional state due to hypercalcaemia. This was found to be secondary to a hyperparathyroid adenoma, which was removed surgically; her symptoms resolved completely. Three months before this presentation she had been admitted with a mild right sided stroke with some residual cognitive impairment. There was no history of hypertension, diabetes, or cardiac arrhythmia.

Physical examination confirmed right sided signs suggestive of previous stroke and revealed a large haematoma overlying the left tibia as a 
result of a fall. Her general condition improved with treatment of a urinary tract infection and constipation, and she began to walk with a frame. Two distinct right sided transient ischaemic attacks slowed her rehabilitation, however, and her cognitive deficits and behaviour remained unchanged.

Routine investigations showed mild renal impairment and a lymphopaenia (PLC = $\left.0.5 \times 10^{9} / 1\right)$. Further immunological tests revealed antinuclear antibody (IgG 100, IgM 800) and antibody to double stranded DNA (IgG 40, IgM 1280). A clotting screen gave normal results and lupus anticoagulant was not detected.

A diagnosis of SLE was made and prednisolone $20 \mathrm{mg}$ daily was started. In view of the difficulty in differentiating vasculitis as a cause of the transient ischaemic attacks from platelet emboli, aspirin $150 \mathrm{mg}$ was given each morning.

Her degree of cognitive impairment was so severe that she was scoring at the lower limit of standardised rating scales. This remained unaffected by steroids, but the change in her behaviour could have indicated a response to steroids: her shouting virtually disappeared, and social responses were generally more appropriate.

\section{Case 4}

An 85 year old widow was admitted from home after a domicillary visit. She had a seven month history of mild fluctuating cognitive impairment and intermittent visual hallucinations. For one month before admission the clinical picture had deteriorated. Her mental state fluctuated, being worse at night; she had become irritable and verbally aggressive, and mobility had declined so that she needed two helpers for walking. The only important medical history was hypertension and recurrent basal cell carcinomas of the head and neck.

Initial assessment of her mental state on the ward confirmed the diagnosis of a subacute confusional state. The confusion fluctuated, but on the whole she appeared disorientated both in time and place, with short term memory impairment and visuospatial deficits.

Results of physical examination were unremarkable and there was no evidence of arthropathy or focal neurological signs. Routine investigations revealed a normochromic, normocytic anaemia of chronic disease and a lymphopaenia (PLC $=0.4 \times 10^{9} / 1$ ). There was mild renal impairment. Further immunological investigations showed antinuclear antibody (IgG $<25$, IgM 100) and antibody to double stranded DNA (IgM 320). The concentration of $\mathrm{C} 3$ degradation products was mildly raised, tests for immunoglobulins and plasma electrophoresis were normal.

A diagnosis of SLE was made, but there was little response to a trial of prednisolone $30 \mathrm{mg}$ daily, which was discontinued after only two weeks. Over the next two months, however, her mental state stabilised without further deterioration, and she was discharged to a rest home.
Case 5

An 83 year old married man was admitted from home to an acute geriatric ward. He had a six month history of declining mobility and falls, accompanying cognitive impairment of a similar duration, and a history of weight loss. He had no psychiatric history, and the only medical history of note was osteoarthritis of both knees and a pruritic skin rash of his hands, arms, and neck 20 years previously.

The ward staff noted that his cognitive state varied considerably. He had particular deficits in orientation, short and long term memory, and visuospatial function.

Apart from the cognitive deficits, the most striking feature of his mental state was bradyphrenia and an accompanying mild bilateral tremor of upper limbs and immobile facies. The rest of his physical examination was unremarkable.

The initial diagnosis was diffuse Lewy body disease, and he was started on levodopa $100 \mathrm{mg}$ and carbidopa $25 \mathrm{mg}$ three times daily. Only marginal improvement of the Parkinsonian features was achieved, and his mental state continued to deteriorate. Investigations showed a lymphopaenia (PLC $=0.7 \times 10^{9} / 1$ ), mild renal impairment, and a raised erythrocyte sedimentation rate $(100 \mathrm{~mm} / \mathrm{h})$. Thyroid function indicated early hypothyroidism (thyroid stimulating hormone $=15 \cdot 2$, thyroxine $=66$ ). Further immunological investigations revealed a concentration of Creactive protein of $20 \mathrm{mg} / 1$ a raised titre of polyclonal IgA, and the presence of antinuclear antibodies (IgM 200, IgG 200) and antibody to double stranded DNA (IgA 10). Brain CT scan showed cerebral atrophy and multiple infarcts.

In the light of these immunological findings the diagnosis was revised to one of NPSLE, and the patient was started on prednisolone $30 \mathrm{mg}$ daily for two months. The response was dramatic; mobility, tremor, and bradyphrenia all improved. Mental state stabilised, with only mild residual deficits. He was discharged home on azathioprine $100 \mathrm{mg}$ daily.

\section{Discussion}

Apart from case 1, all patients had antibody to double stranded DNA shown by a crithidia assay, a test which is highly specific for SLE. C3 degradation products are a sensitive measure of complement activation and are useful in the diagnosis and monitoring of patients with SLE. ${ }^{13}$

In case 1 the patient was being treated with levodopa. The possibility of a drug induced syndrome arises, but primary SLE is the most likely diagnosis for several reasons. Firstly, Parkinsonian symptoms only partially improved with the original prescription of a levodopa preparation, yet resolved with steroids; secondly, organic mental states are rare in drug induced syndromes; and thirdly, other features such as Sjögren's syndrome, myalgia, and arthropathy were also present.

Case 2 illustrates interesting associations with hypothyroidism, which preceded the diag- 
Characteristics of five elderly patients with systemic lupus erythematosus

\begin{tabular}{|c|c|c|c|c|c|c|c|c|}
\hline \multirow{2}{*}{$\begin{array}{l}\text { Case } \\
\text { no }\end{array}$} & \multirow{2}{*}{$\begin{array}{l}\text { Age } \\
\text { (years) }\end{array}$} & \multirow[b]{2}{*}{ Sex } & \multirow{2}{*}{$\begin{array}{l}\text { Duration of symptoms } \\
\text { before diagnosis }\end{array}$} & \multicolumn{3}{|l|}{ Clinical features } & \multirow{2}{*}{$\begin{array}{l}\text { No of } A R A \\
\text { criteria satisfied }\end{array}$} & \multirow{2}{*}{$\begin{array}{l}\text { Response to } \\
\text { steroids }\end{array}$} \\
\hline & & & & Psychiatric & Neurological & Other & & \\
\hline 1 & 75 & $\mathbf{M}$ & 5 years & $\begin{array}{l}\text { Subacute confusional } \\
\text { state, depression }\end{array}$ & Parkinsonism & $\begin{array}{l}\text { Arthropathy, myalgia, } \\
\text { Sjögrens syndrome }\end{array}$ & 3 & Good \\
\hline 2 & 76 & $\mathbf{F}$ & 4 years & $\begin{array}{l}\text { Depression, acute } \\
\text { confusional state }\end{array}$ & $\begin{array}{l}\text { Transient ischaemic } \\
\text { attacks }\end{array}$ & $\begin{array}{l}\text { Hypothyroidism, } \\
\text { inappropriate production } \\
\text { of antidiuretic hormone }\end{array}$ & 3 & Good \\
\hline 3 & 93 & $\mathbf{F}$ & 6 months & Dementia & $\begin{array}{l}\text { Stroke, transient } \\
\text { ischaemic attacks }\end{array}$ & & 3 & Questionable \\
\hline 4 & 85 & $\mathbf{F}$ & 6 months & $\begin{array}{l}\text { Subacute confusional } \\
\text { state }\end{array}$ & & & 3 & Poor \\
\hline 5 & 83 & $\mathbf{M}$ & 6 months & Dementia & Parkinsonism & $\begin{array}{l}\text { Weight loss, } \\
\text { hypothyroidism }\end{array}$ & 3 & Good \\
\hline
\end{tabular}

${ }^{\star}$ Mean age $=82$.

nosis, ${ }^{14}$ and the presence of Libman-Sacks endocarditis at post mortem examination. Libman-Sacks endocarditis has been associated with embolic brain infarcts and the presence of anticardiolipin antibody. ${ }^{15}$

The patient in case 3 had suffered from hyperparathyroidism five years previously. This presented with a subacute confusional state related to the accompanying hypercalcaemia, ${ }^{16}$ and it failed to improve with medical treatment but resolved with parathyroidectomy. No previous link between SLE and hyperparathyroidism has been documented.

SLE may have been incidental and therefore not a cause of the original psychiatric presentation. This is a possibility in cases 3 and 4 . In case 3 , multi-infarct dementia could be a possibility, and aspirin had been started after transient ischaemic attacks. In patient 4 the cause of subacute confusional state was extensively investigated; the most likely alternatives would be multi-infarct dementia or diffuse Lewy body disease. However, only hypertension supported a diagnosis of multi-infarct dementia, and the absence of Parkinsonian features in the presence of characteristic immunology of SLE made diffuse Lewy body disease unlikely. Cases 3, 4, and 5 had relatively short histories, but in cases 1 and 2 the histories were much longer, with the development of more recent neuropsychiatric syndromes (table).

The clinical manifestations of NPSLE suggest two different pathological processes, diffuse in the case of confusional states, epilepsy, and psychosis, and multifocal in cranial and peripheral neuropathy, stroke, and movement disorders. The underlying causes of these clinical presentations are not fully established, but it is believed that the classic immune complex mediated vaculitis accounts for focal changes. In recent years research has concentrated on establishing the pathological mechanisms involved in the more common diffuse process. Autoantibodies are thought to act on neuronal membrane antigens; the evidence for IgG antineuronal antibody, however, is still inconclusive. 23.17 IgM lymphocytotoxic antibody has been implicated in cognitive impairment, ${ }^{18}$ and antiribosomal protein antibody in psychosis. ${ }^{19}$

It has been suggested that patients with evidence of multifocal cerebral disease on CT scan have a poorer prognosis. ${ }^{20}$ Three of our patients (cases 1, 2, 5) had a good response to steroids (table).

Three patients had either focal CT changes suggestive of infarct or a history of a discrete neurological events such as stroke or transient ischaemic attack. Of these three, two had a good response to steroids (cases 2 and 5); the other patient (case 3 ) had a more questionable response. This may be because the steroids have some effect on a diffuse concurrent pathological process-namely, the action of autoantibodies on cell membrane molecules. In support of this theory, a recent MRI study showed that patients with diffuse subcortical abnormalities were more likely to have raised concentrations of serum antibodies to neurofilament, and MRI changes resolved with steroid treatment. ${ }^{21}$

In all cases, including those with a poor response, no physical side effects were reported with steroids or azathioprine. There was also no evidence of worsening mental state or psychosis in any of our patients. However, steroid treatment in this age group is not without difficulties. In one series, complications were reported in $40 \%$ of elderly patients receiving steroids for SLE. ${ }^{7}$ In a large review of adult patients of all ages receiving steroids for various medical conditions, psychiatric syndromes were reported in 5\%; female sex, SLE, and high steroid dose (more than $25 \mathrm{mg}$ prednisolone a day) were all factors associated with increased risk. ${ }^{22}$

In all the cases only three of the American Rheumatism Association's criteria were satisfied; all cases therefore fell short of earning a definite ARA diagnosis of SLE. This supports our contention that the ARA criteria are inadequate for the study of neuropsychiatric SLE in elderly patients. Others have already suggested that the ARA criteria are too strict for making the diagnosis in patients presenting with neuropsychiatric illness and that more weight should be placed on lupus serology in these patients as central nervous system disorder is rare in other rheumatic diseases. ${ }^{23}$

When the ARA criteria are considered individually, the problems of applying their use to elderly patients become apparent. Cutaneous manifestations are less common with increasing age, ${ }^{5624}$ yet they account for four of the 11 criteria. Neurological disorder, common in elderly people, often presents as an isolated event preceding other symptoms. ${ }^{14}$ However, 
the ARA criteria have a very narrow definition of neurological disorder, which consists of only seizures or psychosis. Other neuropsychiatric syndromes in SLE, such as acute and subacute confusional states and depression, are excluded from the criteria yet are common. ${ }^{1-4917}$ Of the patients in our series, two presented with dementia, two with subacute confusional states, and one with depression. The use of lymphopaenia as a marker of haematological disorder of SLE is also problematic in elderly patients. Although lymphopaenia was important in alerting us to the possibility of SLE, it is non-specific and often accompanies common medical conditions such as acute infection, malignancy, malnutrition, and depression. There is also evidence that the total peripheral lymphocyte count falls with ageing as a result of a reduction in circulating $T$ cells. ${ }^{25-27}$ The presence of an abnormal titre of antinuclear antibody could also be misleading as the titre has a tendency to be more positive in elderly patients. $^{28}$

Broader diagnostic criteria such as those suggested by Fries and Holman, ${ }^{29}$ might be more appropriate for the study of SLE in elderly patients. These require evidence of a typical multisystem disorder in combination with immunological abnormalities in the absence of any alternative diagnosis.

\section{Conclusions}

This series of elderly patients presenting with neuropsychiatric SLE to a psychiatry service of old age suggests that SLE in this group is more common than originally thought. Most importantly, SLE is a potentially treatable cause of organic brain disorders. Psychiatrists working with elderly patients need to be alert to the possibility of being asked to see patients with undiagnosed SLE, which presents in an insidious manner with neuropsychiatric features and lacks the other signs of the disorder. In patients with lymphopaenia and antinuclear antibody it is advisable to perform more specific investigations for SLE.

A much larger study needs to be undertaken to determine the prevalence of SLE in old age. This would require more appropriate criteria designed specifically for elderly patients, as continuing to use the ARA criteria could mask a considerable proportion of cases.

1 Bennett $R$, Hughes G, Bywaters $E$, Holt $P$. Neuropsychiatric problems in systemic lupus erythematosus. psychiatric problems

2 Bluestein H. Neuropsychiatric manifestations of systemic lupus erythematosus. $N$ Engl f Med 1987;317:309-11. 3 Breshihan B. CNS lupus. Clinics in Rheumatic Diseases. 1982;8:183-95.

4 Feinglass E, Arrett F, Dorsch C, Zizic T, Stevens M Neuropsychiatric manifestations of systemic lupus erythematosus: diagnosis, clinical spectrum, and relationship to the features of the disease. Medicine 1976;55:323-39.

5 Baer A, Pincus T. Occult systemic lupus erythematosus in elderly men. $\mathcal{F} A M A 1983 ; 249: 3350-2$.

6 Gossat D, Walls R. Systemic lupus erythematosus in late life. Med F A ust 1982;i:297-9.

7 Baker S, Rovira R, Campion E, Mills J. Late onset systemic lupus erythematosus. $A m \mathcal{F}$ Med 1979;66:727-32.

8 Foad B, Sheon R, Kirsner A. Systemic lupus erythematosus in the elderly. Arch Intern Med 1972;130:743-6.

9 Dubois E, Tuffanelli D. Clinical manifestations of systemic lupus erythematosus. $\mathfrak{F A M A} 1964 ; 190: 104-11$.

10 Jonsson $H$, Nived $O$, Sturfelt G, Silman A. Estimating the incidence of systemic lupus erythematosus in a defined population using multiple sources of retrieval. $B r g$ population using multiple

11 Jonsson $H$, Nived $O$, Sturfelt $G$. The effect of age on clinical and serological manifestations in unselected patients with systemic lupus erythematosus. $f$ Rheumatol 1988;15 505-9.

12 Tan E, Cohen A, Fries J, Masi A, McShane D, Rothfield N, et al. The 1982 revised criteria for the classification of systemic lupus erythematosus. Arthritis Rheum 1982;25: 1271-7.

13 Morrow W, Williams D, Ferec C, Casburn-Budd R, Isenburg D, Paice E, et al. The use of C3d as a means of monitoring clinical activity in systemic lupus erythematosus and rheumatoid arthritis. Ann Rheum Dis ematosus and rhe

14 Goh K, Wang F. Thyroid disorders in systemic lupus erythematosus. Ann Rheum Dis 1986;45:579-83.

15 Devinsky O, Petito C, Alonso D. Clinical and neuropathological findings in systemic lupus erythematosus: the role of vasculitis, heart emboli, and thrombocytopenic purpura. Ann Neurol 1988;23:380-4.

16 Byrne E, Hosking D, Jameson C. Serial assessment of serum calcium correlates with mental state. Int $\mathcal{f}$ Geria Psychiat 1987;2:163-8.

17 Breshihan B, Hohmeister R, Cutting J, Travers R, Waldburger M, Black $C$, et al. The neuropsychiatric disorder in systemic lupus erythematosus: evidence for both vascular and immune mechanisms. Ann Rheum Dis 1979;38: and imm.

18 Long A, Denburg S, Carbotte R, Singal D, Denburg J. Serum lymphocytoxic antibodies and neurocognitive function in system
$1990 ; 49: 249-53$

19 Borfa E, Golombek S, Lee D. Association between lupus psychosis and anti-ribosomal p protein antibodies. NEngl $\mathcal{F}$ Med 1987;317:265-71

20 Kaell A, Lee B. The diversity of neurological events in systemic lupus erythematosus. Arch Neurol 1986;43: 273-6.

21 Bell C, Parkington C, Robbins M, Graziano F, Turski P, Kornguth S. Magnetic resonance imaging of central nervous system lesions in patients with lupus erythnervous system lesions in patients with
ematosus. Arthritis Rheum 1991;34:432-41.

22 Lewis DA, Smith RE. Steroid induced psychiatric syndromes. F Affect Dis 1983;5:319-32.

23 Markusse $H$, Vecht $C$. Is neurological disease with positive lupus serology sufficient for a diagnosis of systemic lupus lupus serology sufficient for a diagnosis of system
erythematosus? $\mathrm{Br} \mathcal{Y}$ Rheumatol 1986;25:302-5.

24 Jonsson $H$, Nived $O$, Sturfelt $G$. The effect of age on clinical and serological manifestations in unselected patients with systemic lupus erythematosus. $f$ Rheumatol 1988;15 505-9.

25 De Paoli P, Battistin S, Santini G. Age-related changes in human lymphocyte subsets: progressive reduction of the CD4 CD45R (suppressor inducer) population. Clin Immunol Immunopathol 1988;48:290-6.

26 Alexopoulos C, Babitis P. Age dependence of T lymphocytes. Lancet 1976;i:426.

27 Augener W, Cohen G, Reuter A, Brittenger G. Decrease of T lymphocytes during aging. Lancet 1974; i: 1164 .

28 Hooper B, Whittingham S, Mathews J, MacKay I, Curnow D. Autoimmunity in a rural community. Clin Exp D. Autoimmunity in a

29 Fries JF, Holman HR. Systemic lupus erythematosus. A clinical analysis. In: Smith LH Jr, ed. Major problems in internal medicine. Vol IV. Philadelphia: W B Saunders, 1978:8. 